\title{
Obama's 2012 Facebook Campaign: Political Communication in the Age of the Like Button
}

\author{
Roman Gerodimos \\ Jákup Justinussen
}

\begin{abstract}
This article examines the role of social media in contemporary political communication, focusing on Barack Obama's Facebook campaign in the run-up to the 2012 presidential election. Although there is a growing body of literature on online forms of participation, little research exists on the role of social buttons on Facebook (like, comment, and share) as tools of political voice. We use these native interactive features as indicators of how citizens engage with particular political messages. A content analysis of posts published on Obama's official Facebook page over the two months leading up to Election Day was conducted, along with a detailed measurement of all user interactions for each post. Our analysis indicates that the Obama campaign used Facebook as a tool of top-down promotion, focusing on Obama's personality and as a means of strategically guiding followers to act, rather than as a means of bottom-up empowerment or hybridized coproduction. However, we also found that followers engaged selectively with campaign messages and often interacted more with policy-oriented posts than with promotional ones.
\end{abstract}

KEYWORDS. Barack Obama, campaign, emotions, Facebook, personalization, political communication, presidential election, rhetoric, social media

The 2008 U.S. presidential election marked a significant shift in political campaigning, with the Obama campaign making unprecedented use of social media (Cogburn \& Espinoza-Vasquez, 2011; Lilleker \& Jackson, 2011). Three years later, President Barack Obama broke with convention once again when he publicly announced his reelection bid with a YouTube video and a tweet on April 4th, 2011. The emphasis on different types of social media during the campaign

Roman Gerodimos, PhD, is Principal Lecturer in Global Current Affairs in the Media School at Bournemouth University. His research focuses on the role of digital media in fostering urban coexistence and global citizenship. He is the winner of the 2010 Arthur McDougall Prize for his research on online youth civic engagement. He is the co-editor of The Media, Political Participation and Empowerment (Routledge, 2013) and The Politics of Extreme Austerity: Greece in the Eurozone Crisis (Palgrave, 2015) and has published in journals such as Political Studies, Public Administration, and Information, Communication \& Society. He is founder and convenor of the Greek Politics Specialist Group (GPSG) and a faculty member at the Salzburg Academy on Media \& Global Change.

Jákup Justinussen is a digital marketing and communications consultant in the Faroe Islands and recently graduated with an MSc in Digital Marketing from the University of Southampton. He holds a BA (Hons) in Communication \& Media from Bournemouth University, where he won the 2013 Carol Burns prize.

Address correspondence to: Roman Gerodimos, The Media School, Bournemouth University, Talbot Campus, Fern Barrow, Poole BH12 5BB, UK (E-mail: rgerodimos@bournemouth.ac.uk).

Color versions of one or more of the figures in the article can be found online at www.tandfonline.com/ witp 
reflects their increasing presence in people's 30 daily lives and their potential role in facilitating more direct and interactive communication between politicians and citizens. Citizens increasingly access social media for political news and to share their opinion (Rainie \& Smith,

35 2012; Sweetser \& Lariscy, 2008). To what extent, though, does this intensive activity across digital platforms constitute a paradigm shift in terms of civic engagement with political discourse?

40 An increasingly rich body of literature has been looking at online political campaigns in order to establish whether politicians are utilizing the Internet's potential to empower citizens and reduce the democratic deficit. Despite extensive claims about a shift to a new paradigm of civic empowerment, existing research has yet to confirm these hopes: Larsson (2013) found that, overall, citizens prefer to stay consumers, and political actors opt for a rather conservative

50 use of the Web. The extent to which increasing levels of access, interaction, and civic literacy can create an "architecture of participation" (Jackson \& Lilleker, 2009, p. 232) that will force politicians to engage in more meaningful ways 55 remains to be seen.

This paper looks at Barack Obama's campaign for the 2012 presidential election, focusing on its presence and content on Facebook, as well as the response of followers to particu-

60 lar types of rhetorical strategy and post content. The premise of our study is that users selectively interact with some posts and not with others through Facebook's native features (likes, comments, and shares), and that some messages

65 capture their interest while others are deemed not interesting enough to engage with. For that purpose, we analyzed the Obama campaign's communication content on his official Facebook page (www.facebook.com/BarackObama) in the

70 run-up to the 2012 election, and how users engaged with those messages. In addition to providing us with a glimpse into the president's broader reelection campaign strategy, this quest can also inform our understanding of politi-

75 cal communication through social media and the extent to which this constitutes a fundamentally more interactive paradigm of civic engagement.
Despite the proliferation of studies on online political communication, there is little empirical work on engagement through social media (Carlisle \& Patton, 2013). Existing studies focus either on the strategy of particular campaigns or on the effects of Internet/social media use on social capital and political participation in general. Many of these studies are skeptical about the existence of any particularly positive or paradigm-shifting effects, although Vaccari (2010) argues that we may be witnessing the emergence of a hybridized model of top-down strategic control and bottom-up civic empowerment during political campaigns. This study brings together these two conceptual strands to examine the content of Obama's 2012 Facebook campaign and compare it to users' engagement with particular types of messages. There are now several published studies on Obama's 2008 campaign, whose findings and questions regarding innovation, interactivity (or lack of), empowerment (or lack), and different forms of strategic control (e.g., BaldwinPhilippi, 2012) can be used as a benchmark against which to evaluate the 2012 campaign.

\section{THE DIGITIZATION OF "THE PERMANENT CAMPAIGN” AND THE OBAMA PHENOMENON}

The gradual professionalization of political communication over the last several decades (Negrine \& Lilleker, 2002) was a precursor to a rapid and radical shift to a much more intense, strategic, and personalized level of campaigning via new media that has taken place in the last decade. The digitization of the "permanent campaign" has allowed political parties to reach out to both loyal and swing voters throughout the electoral cycle, renewing early hopes regarding the potential of the Web to facilitate dialogic communication-and thus a more substantive relationship-between elected representatives and citizens (Kent \& Taylor, 1998).

Campaign Web sites were originally used to provide information and mobilize constituents. Howard Dean was the first to give the Internet a prominent role in his campaign in the runup to the 2004 presidential election (Compton, 
2008), but critics have posited that his blog was merely a facade of interactivity because he made interactive tools available, but ignored comments from supporters on his blog (Sweetser 130 \& Lariscy, 2008). Online campaigning was still at an early stage, with Web sites being treated as "static campaign flyers" (Endres \& Warnick, 2004, p. 323) and used merely for disseminating information rather than building dialogue.

135 The extent to which the use of social media, e-mail campaigns, and widespread grassroots mobilization since 2004 and in particular since 2008 signify a return to a paradigm of more meaningful direct communication between can140 didates and voters is still debated. Yet, it is clear that the Internet has had an undeniable impact on the ways and means through which the public engages with politics. In a postmortem about the 2008 election, Daou (cited in Metzgar and

145 Maruggi, 2009) wrote that "never before have so many people conversed publicly and never before has the global discourse been so accessible, recursive and durable" (p. 161). As Pearson and O'Connell (2012) note, "[i]n 2009, Twitter

150 was a novelty in politics. In 2012, it's a necessity." This echoes the fact that nearly twice as many people used social networking sites (SNSs) in 2011 compared to 2008 (Hampton, Goulet, Rainie, \& Purcell, 2011), with Twitter 155 users increasing from 3 million to 500 million (Semiocast, 2012), and Facebook exceeding 1 billion users in 2012 (Facebook, 2013).

Much research has been carried out on the unprecedented use of social media in the 1602008 U.S. election, making Obama's campaign a seminal case study of social media use in politics (Cogburn \& Espinoza-Vasquez, 2011; Sweetser \& Lariscy, 2008; Vaccari 2010; Woolley, Limperos, \& Oliver, 2010). At some 165 point, the 2008 Obama campaign employed up to 100 staff members to work on his social media presence (Hong \& Nadler, 2012). In the 2012 election, the prevalence of social media increased even further (see Table 1). Donating 170 was made significantly easier when the Quick Donate function was implemented, wherein a donor's payment information could be stored so that next time they were prompted to donate through an e-mail, text message, or on social media, they could do so with a single click. The
TABLE 1. Barack Obama's Online Campaigning in 2012 Compared to 2008

\begin{tabular}{lll}
\hline & \multicolumn{1}{c}{2008} & \multicolumn{1}{c}{2012} \\
\hline $\begin{array}{l}\text { Facebook fans } \\
\text { Digital } \\
\text { fund-raising }\end{array}$ & 2.4 million & 32 million \\
$\begin{array}{l}\$ 533 \mathrm{~m}^{*} \\
\text { Donations } \\
\text { under } \$ 200\end{array}$ & $\begin{array}{r}\text { 45\% of total } \\
\text { donations }\end{array}$ & $\begin{array}{r}67 \% \text { of total } \\
\text { donations }\end{array}$ \\
\hline
\end{tabular}

*In 2012 prices

Obama campaign utilized Twitter's Q\&A sessions feature (http://askobama.twitter.com) and created an "Ask Me Anything" thread on Reddit (Reddit, 2012).

Although the literature on the use of social media during the 2012 election campaign is only now emerging, several questions and concerns are being posed that are consistent with points raised by previous studies in the United States and Europe. Based on a series of in-depth interviews with 2012 campaign consultants and strategists, Serazio's (2014) study shows "how campaign operatives labor to manage political discourse and news agenda(s) in ways antithetical to [the ideals of the Habermasian public sphere], given the opportunities and challenges that new media technologies afford" (p. 759); in an effort to attract swing voters who tend to tune out partisan messages, the president of a political advertising agency interviewed by Serazio admits that "you have to figure out a way of really disassociating yourself from politics to try to get their attention in the first place" (p. 751). Shifting away from political debates appears to help not only attract people's attention but also control the message. Following a comparison of Barack Obama's and Mitt Romney's Facebook output in the run-up to the 2012 election, Bronstein (2013) concludes that "the main advantage of fandom politics over traditional politics is that it discourages dissent and encourages affective allegiances, i.e., it is easier for the candidate to maintain the support of their audience if they like him or her" (p. 185).

Other recent studies on Obama's use of digital media in 2008 and during his presidency produced mixed results regarding the paradigmshifting nature of his communications output. 
In a review of election campaigning across four

liberal democracies, Lilleker and Jackson (2011) found that in all cases (including Obama's original campaign), candidates' Web sites "were geared towards furthering the campaign and not enhancing public engagement with the democratic process" (p. 190), although they also note that the only example of bottom-up communication was observed on Barack Obama's blog. Similarly, Katz, Barris, and Jain (2013) found that despite "the impression of responsiveness"

225 (p. 108), the White House has only created dialogical opportunities that do not require more than a nominal reaction.

However, we still need to establish the precise rhetorical tools utilized by the Obama campaign

230 to better understand the extent to which that discourse was close-ended and strategic or inviting of further engagement. Kienpointner (2013) argues that Obama has successfully managed to incorporate rational argumentation into his

235 political rhetoric and, by strategically "maneuvering," to overcome the polarization of partisan discourse, that is, combining the normative ideal of rational deliberation with efficient persuasion. We thus apply the classic Aristotelian model of 240 rhetorical strategy (logos, ethos, pathos), which has proven to still be a valuable tool for the understanding of political action in contemporary settings (Martin, 2013).

Past political campaigns have used a vari-

245 ety of rhetorical tools such as informing, building relationships with the voter, personal appeal (directly addressing the audience or using the imperative mood), building a candidate's image, calls to action, denigrating an opponent, and defending against an opponent's attacks (Sweetser \& Lariscy, 2008; Trammell, Williams, Postelnicu, \& Landreville, 2006). It has also been shown that emotional appeals can be particularly impactful on how citizens respond to 255 political messages (Brader, 2005). It is well known that in 2008, Obama put strong emphasis on hope and looking forward. Indeed, many studies have looked at the rhetoric and language of political candidates, but research is only just

260 beginning to look into the nature of interactive features on social media (e.g., Bronstein, 2013; Gerlitz \& Helmond, 2013; John, 2013), and there are no known studies examining these in comparison to the rhetoric and content used in Facebook posts, including photographs.

\section{EMERGING PATTERNS OF ONLINE CIVIC ENGAGEMENT}

The question of whether digital campaigns utilize the medium's capacity for democratic dialogue and even coproduction of policy (Jackson \& Lilleker, 2009), or whether they stick to one-way communication with few participatory features, is part of a broader debate between proponents of the theory of innovation - the view that social media provide us with space for positive, fact-checked, and decentralized debate, effectively signaling a new paradigm of civic engagement, and those who support the theory of normalization - the view that online campaigns and civic attitudes merely replicate offline traits and phenomena, such as strategic control, candidate focus, and negative campaigning (Larsson, 2013). The role and attitudes of citizens - and how their civic activities can be facilitated or hampered by the medium's own filters-are also crucial factors.

It has been argued that social media empower voters, and in particular give young people a tool to express their civic voices. A study by Wells and Dudash (2007) showed that two of the most popular sources for political information among young voters are talking to others and the Internet. In fact, $27 \%$ of 18 - to 29 -year-olds even say that SNSs make more of an impact than in-person advocacy in political campaigning (Harvard University Institute of Politics, 2011). The same survey also shows that young voters looked first to national newspapers for political news on the 2012 election campaign, then to what friends shared on Facebook, followed by official Facebook campaign pages. Other studies expand this to all ages, revealing that voters' political attitudes and behavior are influenced by everyday conversations with family members or complete strangers (Himelboim, Lariscy, Tinkham, \& Sweetser, 2012; Lilleker, 2006). Some have expressed concerns about the fact that the Internet seems to favor homophily and selective exposure, bringing like-minded people together and functioning only to reinforce their
270 
preexisting beliefs, a phenomenon accentuated by sophisticated algorithms that are particularly instrumental across social media, creating a "filter bubble" that restricts the range of perspec315 tives encountered by citizens online (Pariser, 2011).

Interestingly, recent studies (e.g., Vaccari, 2013) show that online political campaigns have also become more efficient at improving recep320 tion and acceptance of political messages. This is effectively done when individuals see information diffused through low-threshold activities by supporters, for example, seeing content shared by peers. Also, reinforcement seems

325 less relevant when considering undecided voters, because they are yet to be persuaded. They seek emotional and economic stimuli and cues from the campaign (Lilleker, 2006). However, research has yet to look at how users engage with specific political messages on SNSs and what type of content is deemed more worthy of sharing.

Digital tools themselves can be used to create or contribute to a public conversation among voters, and even though such actions do not necessarily qualify as political conversations, the increasing newsworthiness of viral posts (such as the photo of Barack and Michelle Obama hugging at a campaign rally, which was

340 posted after the 2012 election was called and became the most tweeted photo to date) is a reminder that user responses to social media content have become a distinct cultural phenomenon in their own right. On Facebook, users

345 can express affirmation of content with a like, voice their opinion with a comment, or share content with their own network. These metrics can be studied to understand what type of political content engages people, among other potential implications (e.g., impact on public policy and institutional legitimacy) and potential knock-on effects (e.g., benefits for political awareness and spillover to active, offline participation), which fall outside the scope of the 355 present paper. Facebook's interface, including the architecture of the News Feed (text and image posts are structurally equal, in contrast to other social media platforms) and the usability of the platform's native features (commenting is while liking and sharing only require a single click), makes it a particularly interesting case from a political communication perspective.

The conversation on Facebook is partly facilitated by posting content, and partly by engaging with existing content through the use of social buttons. These facilitate cross-syndication and quick dissemination of Web content (Gerlitz \& Helmond, 2013). The like button was originally introduced to "replace short affective statements like 'Awesome' and 'Congrats!'” (Gerlitz \& Helmond, 2013, p. 5). Little research exists on the motivation behind why people like on Facebook, but the intuitive assumption is that the number of likes implies exposure, attention, and some sort of affirmation, ratification, or endorsement of what is posted. Essentially, a post with many interactions has evidently grabbed more attention and spread more widely, whereas a post with fewer interactions has not been deemed worthy or interesting to engage with. Sharing on social media is an active practice of communication and distribution. It is not sharing in the traditional sense where you give something, so that you consequently have less. It is a nonsacrificial act of participation, benefiting from the positive connotations of the traditional concept of sharing (John, 2013). Hence, it is a less costly and lower-level form of participation, but still signifies dissemination, exposure, and citizen dialogue.

Having noted that, SNSs are merely a platform facilitating communication to and between voters. Pearson and O'Connell (2012) argue that it is not the number of followers that determines one's influence on Twitter; it is how one uses those 140 letters. Metzgar and Maruggi (2009) contend that social media is just a tool and cannot replace "message, motivation, or strategy" (p. 141). Similarly, Vaccari (2010) reiterates the role of contextual factors, arguing that technology is merely the driver of preexisting motivations. Hence, the medium-specific aspects of a particular campaign — such as Facebook's native features-ought to be examined in conjunction with fundamental social, cultural, political, and psychological aspects of political communication and engagement.

It could be argued that the emergence of civic consumerism-which this type of user-oriented 
selective online engagement is part of-poses challenges for democratic engagement and traditional notions of civic duty, because citizens and especially young people demand to see 415 the relevance of issues to their own everyday lives (Gerodimos, 2008, 2012). Facebook founder Mark Zuckerberg's modus operandi, that is, that "[a] squirrel dying in front of your house may be more relevant to your inter-

420 ests right now than people dying in Africa" (Kirkpatrick, 2010, p. 296) raises further questions about the role of empathy and values in contemporary civic engagement through social media.

\section{RESEARCH QUESTIONS AND DESIGN}

This study seeks to examine how people respond to specific political messages online using social buttons as metrics of civic engagement. Based on this context, our two starting

430 assumptions are that (a) Facebook interactions such as liking, commenting and sharing are part of the everyday conversation that represents and shapes individuals' political attitudes; and (b) the number of interactions on Facebook

435 posts more or less reflects what captures followers' attention, at least at a basic quantitative level. Focusing on the 2012 Obama campaign on Facebook, the aim of the study is to analyze the content of campaign posts and the response of

440 followers and, more broadly, to examine what these patterns of interaction tell us about the depth and interactivity of online political communication and the potential for meaningful civic engagement.

445 In particular we pose the following research questions:

RQ1. Content/Strategy: What were the main types of posts, themes, and rhetorical tools used by the Obama

450 campaign on Facebook, and did these constitute a top-down strategic communications output or an attempt to foster two-way engagement with voters?
RQ2. Reception/Engagement: Which of 455 the frames, policy areas, and rhetorical devices used were most successful in terms of Facebook follower engagement (measured through the number of likes, comments, and shares)?

For the purposes of this study we conducted a content analysis of all 166 posts $^{1}$ published on the Obama campaign's official Facebook page over 67 days, leading up to Election Day, that is, from September 1 to November 6, 2012. Three of these posts were photo albums and were not included in the final coding $(N=163)$ as they were classified as folders (groups of many pictures). Every post was recorded onto a spreadsheet, with text, picture, video, and hyperlink as appropriate, and, along with these, the number of interactions (see Figure 1). The coding process involved looking at the impact of content (themes and rhetoric), structure (graphics, text length), and strategy (frequency of posts, temporal context, which day of the week posts were published) on the number of likes, comments, and shares that each post received. A higher number of interactions was assumed to indicate a higher level of engagement with the post content by Facebook users.

The codes used were a mixture of select codes from past literature along with codes deduced from the content and rhetoric of the posts. For example, Benoit's functional approach, which examines the division between acclaims, attacks, and defense strategies (Benoit \& Benoit, 2005) was employed to compare sentiment with past campaign communication strategies. Additionally, the coding scheme featured six categories deduced from the samples: post structure, Aristotelian rhetoric, rhetorical devices, policy themes, picture content, and call to action. These were further divided into 46 different codes, which were interpreted in dichotomous categories, sorted by present (1) or absent (0) for each post (Trammell et al., 2006). (For intercoder reliability see Table 2.) The data was reviewed twice to refine the discovered codes 
FIGURE 1. Sample post from Barack Obama's official Facebook page.

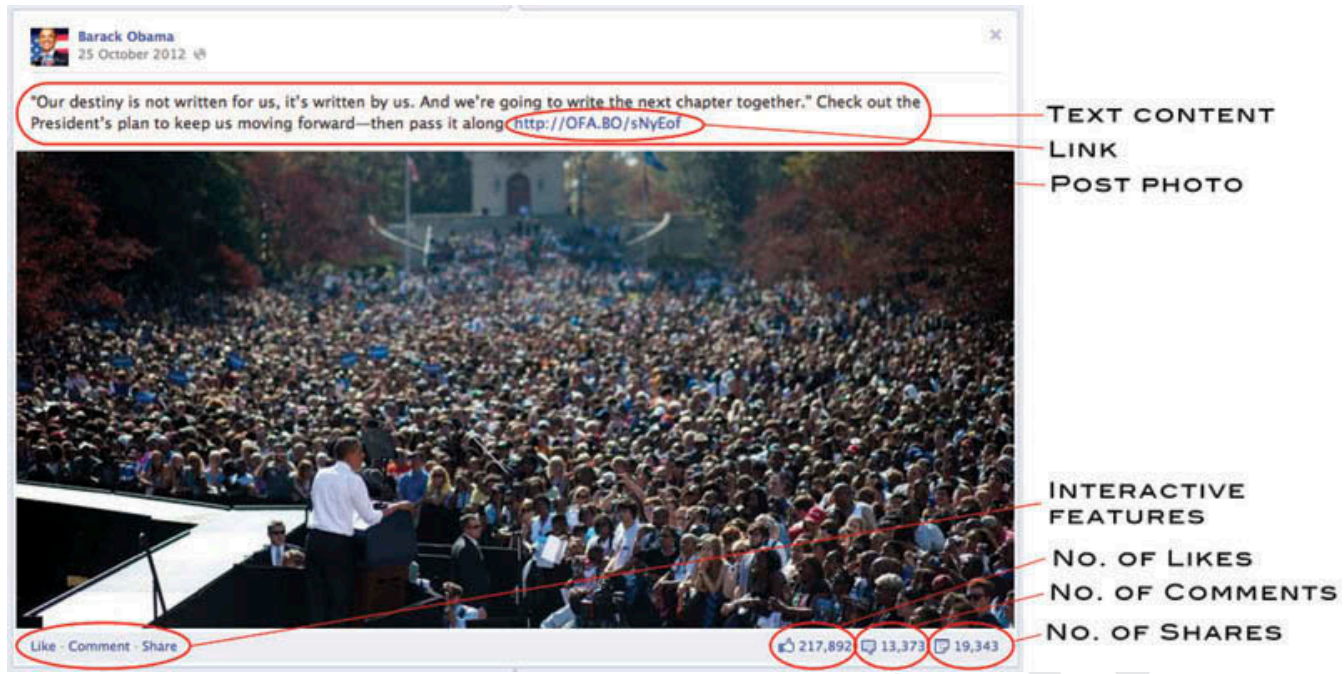

TABLE 2. Coding Categories for Content Analysis and Intercoder Reliability

\begin{tabular}{|c|c|c|}
\hline Coding categories & Variables & $\begin{array}{l}\text { Cohen's } \\
\text { kappa* }\end{array}$ \\
\hline Benoit's functional approach & $\begin{array}{l}\text { Acclaim (person/policy) } \\
\text { Attack (person/policy), Defense }\end{array}$ & $\begin{array}{l}.732(p=.005) \\
1(p<.001)\end{array}$ \\
\hline \multirow[t]{2}{*}{ Aristotelian rhetoric } & Logic, None & $1(p<.001)$ \\
\hline & $\begin{array}{l}\text { Credibility } \\
\text { Emotion }\end{array}$ & $\begin{array}{l}.857(p=.001) \\
.865(p=.001)\end{array}$ \\
\hline \multirow[t]{3}{*}{ Rhetorical device } & $\begin{array}{l}\text { Question, Policy statement, Fact/statistic, Collective } \\
\text { appeal, Personal appeal, Quote, Humor, Celebrity } \\
\text { endorsement }\end{array}$ & $1(p<.001)$ \\
\hline & Call to Action & $.815(p=.001)$ \\
\hline & Urgency & $.865(p=.001)$ \\
\hline \multirow[t]{2}{*}{ Call to action } & $\begin{array}{l}\text { Donate, Buy/offer, Competition, Vote, Support/Get } \\
\text { involved, Find out more }\end{array}$ & $1(p<.001)$ \\
\hline & Share & $.815(p=.001)$ \\
\hline Policy themes & $\begin{array}{l}\text { Foreign policy, Unemployment, Economy, Health care, } \\
\text { Energy, Education, Taxes, Women's rights }\end{array}$ & $1(p<.001)$ \\
\hline Post structure & Video, Picture, Text only, Hyperlink & $1(p<.001)$ \\
\hline Photo content & $\begin{array}{l}\text { Barack Obama, Michelle Obama, Daughters, Joe Biden, } \\
\text { People, Politicians, Promotion, Policy, Quote, Prompt to } \\
\text { share }\end{array}$ & $1(p<.001)$ \\
\hline
\end{tabular}

*On a random $10 \%$ of the sample, two coders, blind coding

and categories (Saldaña, 2009). Because pictures are very prominent in Facebook posts, often being the main carrier of a message or complementing the written text, the coding pro-

cess looked at the picture and text in a post combined. However, this merely involved looking at the textual content and explicit elements in a picture (Table 2), and did not interpret connotations or associations that a picture might evoke in a reader. Video and link content was 
not analyzed, because this is not immediately visible to the user browsing the posts on the Obama campaign's Facebook page. These elements require a level of active (albeit minimal) effort from the user-opening the link or pressing the play button-who only then is exposed to the message contained therein.

For the data analysis we initially used MannWhitney's U to compare the means of likes, comments, and shares across all the dichotomous coding categories. We then run multiple regression tests, treating the various post content/structure features as independent variables and likes $\left(R^{2}=.636\right)$, comments $\left(R^{2}=\right.$ $.466)$, and shares $\left(R^{2}=.461\right)$ as the dependent variable. Based on those findings we then run an analysis of covariance (ANCOVA) test to further cross-check the impact of various factors on likes, comments, and shares, while control-

530 ling for certain variables that appeared to have a significant effect.

\section{FINDINGS}

Our analysis indicates that, overall, the Obama campaign treated Facebook as a tool of top-down promotion, as opposed to a means of substantive civic interaction. Furthermore, while messages were highly personalized, both in terms of focusing on Obama's personality and directly addressing the user, they focused more on the symbolic and affective aspects of political communication than on political argumentation and issue-oriented campaigning. However, interestingly, campaign followers were quite selective about which messages they engaged with, often rejecting certain types of posts (if we accept the study's premise that not interacting with a post can be considered an indication of rejection or selective engagement on the part of Facebook users). Before presenting the substantive findings in more detail, we first outline the frequency, volume, and intensity of campaign messages and user interactions across the two-month period.

\section{Campaign and User Interaction Overview}

Although the number of page likes (i.e., the total number of users who effectively subscribed to Barack Obama's Facebook page) increased from 28 million in early September of 2008 to 31.8 million in early November (see Figure 2) meaning that an increased number of users were exposed to the president's messages in their Facebook News Feed - the number of post interactions remained mainly steady with a slowly increasing trend line and large fluctuations. Consistency in the social media communication strategy was apparent in that two to three posts were published on most days, with an average length of 19.8 words each (see Figure 3). Limiting Facebook communications to such a

FIGURE 2. Time line-Total likes of Obama's official Facebook page.

Total likes

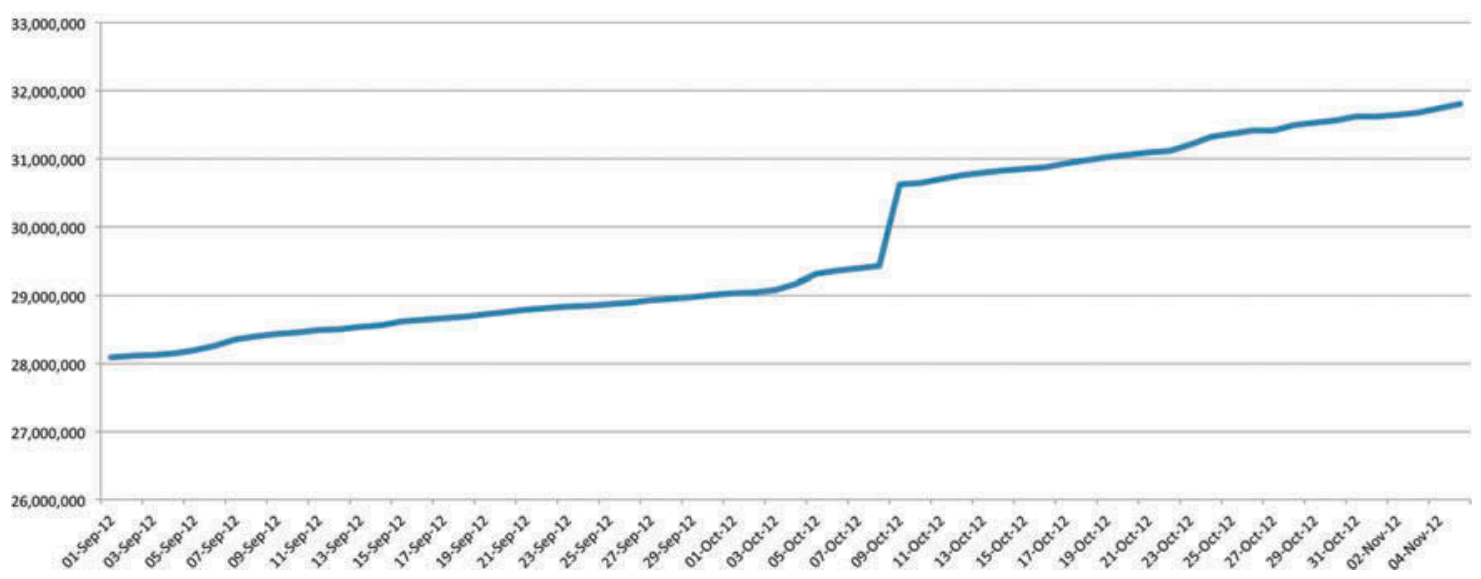

Source: InsideFacebook.com 2012 
FIGURE 3. Number of Facebook posts published daily by the Obama campaign (September 1st to November 6th, 2012).

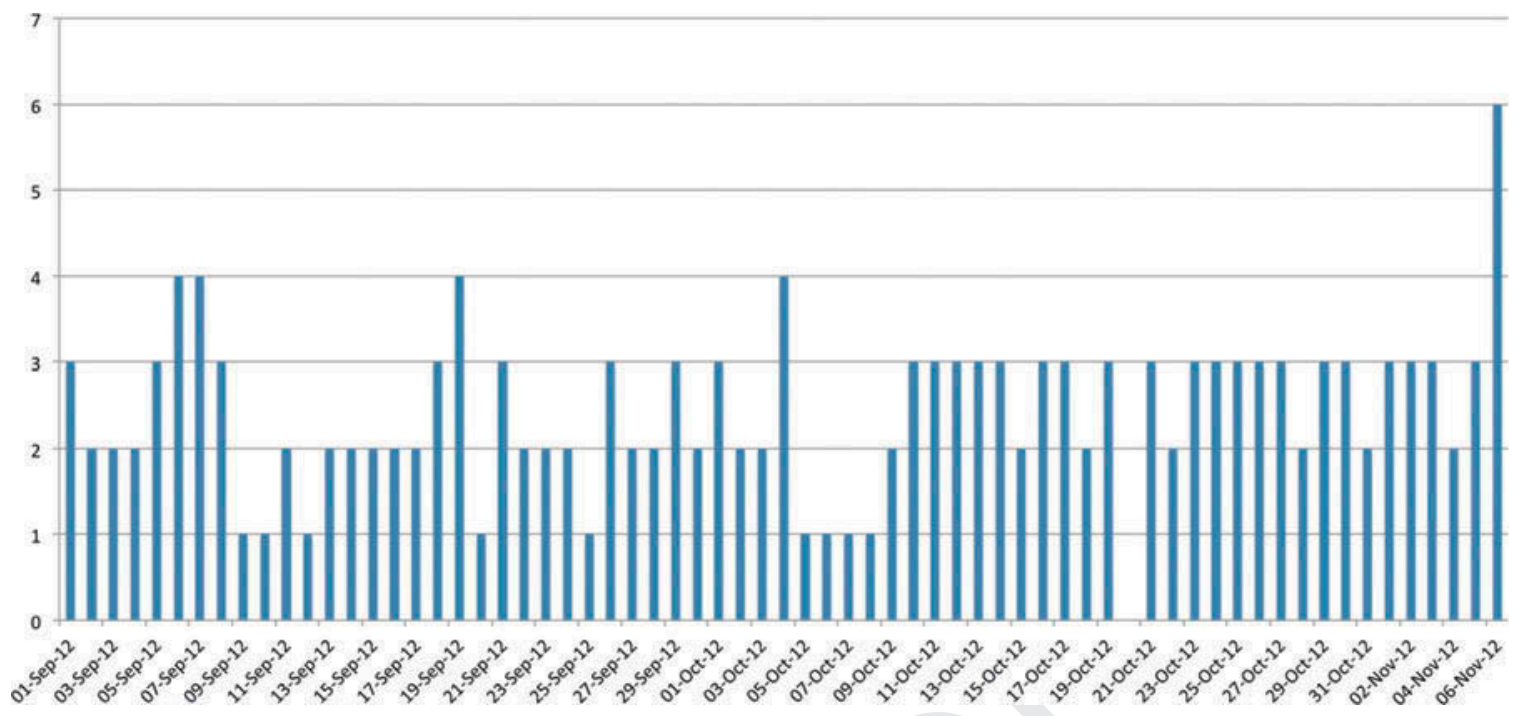

small core of posts per day maintains a stable amount of output in order to avoid the contrast between busy and slow news days (or between periods of aggressive or positive and cautious or defensive campaigning); additionally, it ensures

575 that followers' attention is not diluted, given especially the mechanics of Facebook's personalization algorithm, which prioritizes and manipulates the visibility of posts on a user's News Feed (Pariser, 2011).

The stable and relatively small number of posts comes into stark contrast with the highly volatile and energetic user interaction with those posts (see Figure 4). Beyond the weekly flow of likes (peaking on Wednesdays and dipping on Saturdays), comments (dipping on Sundays), and shares (dipping on Fridays to Sundays), the occasional peaks in interactions highlight key events, such as the debates, the Obamas' 20th anniversary, and Election Day. Although it 590 is obvious that this graph only captures events mentioned by the campaign itself, it still gives us an interesting overview of how followers interacted with these events. For example, the day after the third debate (October 23, 2012), a Obama won the final debate ..." and the number of interactions peaked for likes, comments, and shares. Furthermore, the comparative

overlay of all likes, shares, and comments across the 67 days of analysis in Figure 4 shows that people interact differently with different posts. For example, some posts peak in comments but not in likes and shares.

Although a like is the easiest way to engage (it only requires a click), and therefore receives significantly more interactions than comments or shares, the variation across dates and events suggests that the three interactive features are different not only in terms of effort. As demonstrated below, they also signify different meanings and constitute different ways of engaging with a given message. This may be more applicable to younger voters in particular, who are more likely to perceive online interactions as a viable form of political participation: a like is arguably a way of affirming or ratifying that which is said; a comment allows for voicing one's opinion, and a share is about sharing information with one's own connections. The changed perception of political participation is also evident in that, according to some studies, young social media users are not as interested in more costly activities such as fund-raising, but rather in debating and establishing relationships with the candidate and fellow supporters, which can be confined to mere interactions on a social media platform (Sweetser \& Lariscy, 2008). 
FIGURE 4. Overlay of likes, comments, and shares per post (September 1st to November 6th, 2012).

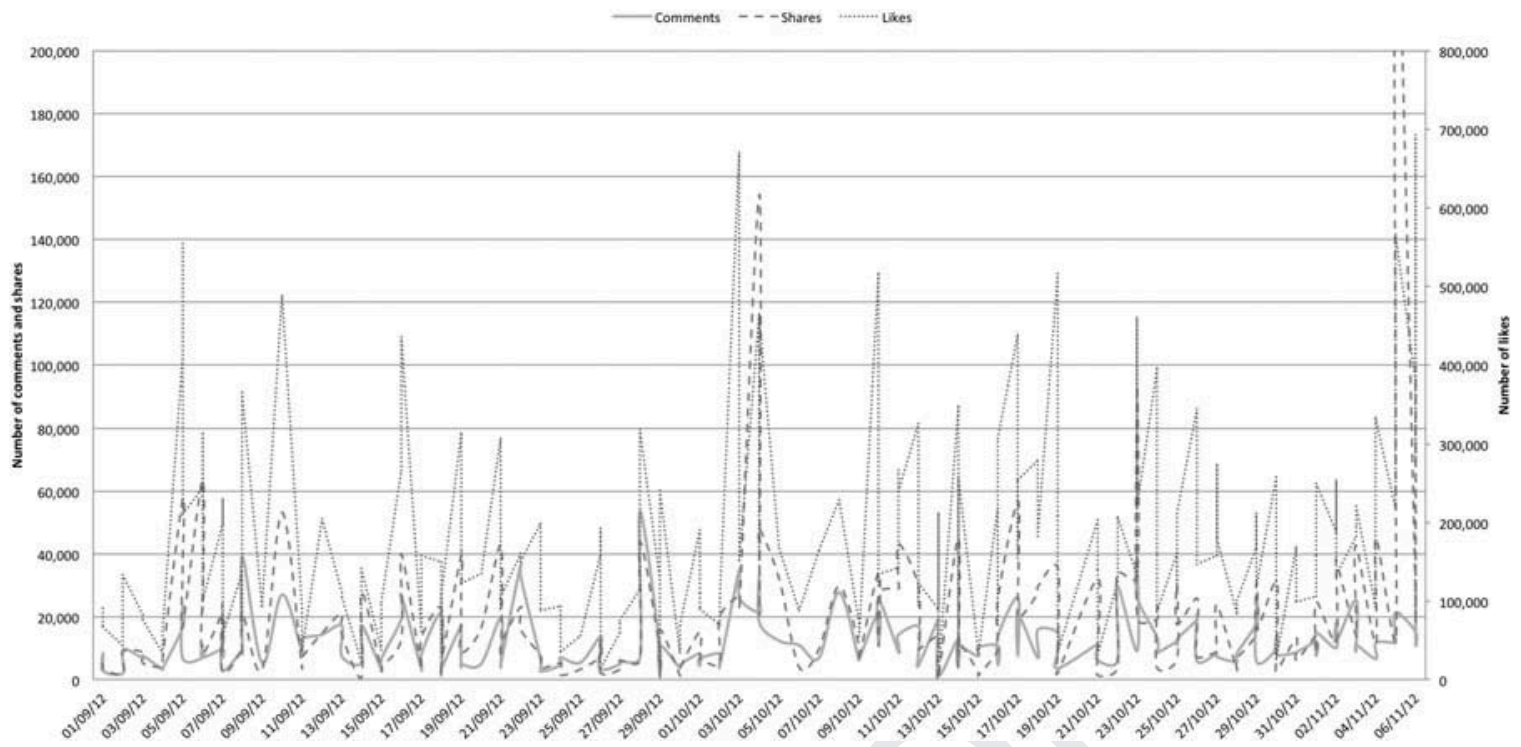

\section{Campaign Content and Strategy:}

630 Facebook as a Tool of Top-Down Personalized Promotion

The overwhelming majority of the messages posted by the campaign in the 67 days before the 2012 election were picture posts, that is, 635 they featured a single photo, usually along with an accompanying caption, text, or commentary (see Table 3). This aligns well with Facebook's ethos about sharing visual content, because the platform recently announced 640 a design change to make picture content more prominent (Forbes, 2013). More than half of the

TABLE 3. User Interaction with Different Post Formats

\begin{tabular}{lcccc}
\hline $\begin{array}{l}\text { All posts } \\
(N=163)\end{array}$ & Picture & Video & Text-only & Hyperlink \\
\hline $\mathbf{n}$ & 154 & 7 & 2 & 125 \\
$\%$ & 94.5 & 4.3 & 1.2 & 76.7 \\
$\begin{array}{c}\text { Likes } \\
\text { (Mean) }\end{array}$ & 195,252 & 38,468 & 126,065 & 174,146 \\
$\begin{array}{c}\text { Comments } \\
\text { (Mean) }\end{array}$ & 12,782 & 3,826 & 6,169 & 12,509 \\
$\begin{array}{c}\text { Shares } \\
\text { (Mean) }\end{array}$ & 21,842 & 4,856 & 4,835 & 17,753 \\
\hline
\end{tabular}

photo posts featured Barack Obama himselfactively speaking, hugging supporters, on the phone, or with an affective appeal where he is with his family or with a clear expression of readiness to take on a second term-while a further $13 \%$ featured his wife and/or daughters alone (see Table 4). Very few videos are posted and the vast majority of hyperlinks link to the campaign Web site (www.barackobama. com) or other campaign sites, with only a few linking to the following external sources: White House Blog, Beyoncé Web site (endorsement),

TABLE 4. Applying Benoit's Functional Approach

\begin{tabular}{lrrrcr}
\hline $\begin{array}{l}\text { Overall posts } \\
(N=163)\end{array}$ & $n$ & $\%$ & $\begin{array}{c}\text { Mean likes } \\
\text { per post }\end{array}$ & $\begin{array}{c}\text { Mean } \\
\text { comments } \\
\text { per post }\end{array}$ & $\begin{array}{c}\text { Mean } \\
\text { shares } \\
\text { per post }\end{array}$ \\
\hline Acclaims & 78 & 47.9 & 213,944 & 13,331 & 21,672 \\
character & 49 & 30.1 & 239,481 & 13,283 & 20,935 \\
policy & 29 & 17.8 & 171,989 & 13,954 & 23,290 \\
Attacks & 31 & 19.0 & 178,502 & 15,656 & 24,455 \\
character & 15 & 9.2 & 161,980 & 13,142 & 19,484 \\
policy & 17 & 10.4 & 190,389 & 17,492 & 29,315 \\
Defense & 0 & 0 & - & - & - \\
\hline
\end{tabular}


Red Cross donations (Hurricane Sandy), and 655 The Daily Show (interview with Obama).

Moving on to the content of the text accompanying the images, we found that Obama's 2012 Facebook campaign was mostly positive and avoided highly polarizing or negative attacks. Using Benoit's functional approach in the coding process allowed us to draw comparisons to previous studies using the same theoretical framework (Benoit \& Benoit, 2005; Compton, 2008; Sweetser \& Lariscy, 2008;

665 Trammell et al., 2006). No defensive responses were made to Romney's attacks (although the "Obama Truth Team" Facebook page was more concerned with deflecting attacks and countermaneuvers), which is somewhat different from

670 previous campaigns, although, even in the past, defensive responses were only used on a small scale (Compton, 2008).

Nearly half of the posts $(N=163)$ on the official Obama Facebook page were acclaims

675 followed by a considerably smaller number of opponent attacks (Table 4). Compared to the 2008 social media campaign, where the divide between character- and policy-focused acclaims was about $55 \% / 45 \%$, respectively (Compton,

680 2008), stronger emphasis was placed on character acclaims in the 2012 election and less on policy $(62 \% / 38 \%)$. Furthermore, while $78.8 \%$ of policy statements in the 2004 Bush versus Kerry campaign were attacks against the opponent, 685 only $52 \%$ were attacks against character and policy in this campaign. Sixty-four percent of policy statements included acclaims of Obama's own character and policies, suggesting a more positive tone. This is consistent with previous 690 studies of both the 2008 (Lilleker \& Jackson, 2011) and the 2012 (Bronstein, 2013) campaigns, which found that the Obama team opted for a broadcast message of hope and enthusiasm, while only using negative campaign695 ing through "under the radar" microtargeting (Serazio, 2014, p. 745).

In terms of the rhetorical tools employed, the case for Obama is mostly built on emotions (pathos) and credibility (ethos) and less so on rational arguments (logos). In fact three-quarters of character acclaims use emotionally charged phrases such as "Obama has revealed himself to be a man who cares about all Americans," ". . . a president who stands up for all Americans . . . ," and "President Obama's leadership has made America stronger, safer, and more secure ..." A key vehicle for the framing of Obama's credibility was quotes: nearly one-third of all posts used quotes to make a point and the great majority of them contained some form of emotive language and credibility appeal. Only one-quarter of posts contained policy statements, which is very similar to the proportion of policy messages featuring in blogs during the 2004 campaign (Trammell et al., 2006).

Given the highly personalized nature of the American political system, it is not unusual for a presidential campaign to focus on the person of the individual candidate as opposed to more political, institutional, or processual aspects of the campaign. Even so, our analysis shows that Obama's reelection campaign on Facebook focused predominantly on his personality and family, rather than on his policies, ideas, track record, or opponent, which is somewhat surprising for a sitting president whose first term featured historic executive, legislative, and judicial debates and decisions.

Crucially, policy posts were not framed as opportunities for substantive debate or engagement, that is, "conversation starters"; they were used as hooks for a call to action, such as sharing (50\%), showing support (7\%), voting (7\%), and finding out more $(2.4 \%)$. This finding reflects more broadly the entire discourse of the campaign, which was close-ended, promotional, and highly guarded or controlled. For example, out of 163 posts, only nine contained any type of question, perhaps a somewhat crude but still important indicator of whether the discourse figuratively or literally attempts to engage the audience in a substantive discussion. Even more tellingly, out of those nine questions only one could be characterized as potentially substantive, but even that was tied to a call for action ("Why are you voting for President Obama? Leave your No. 1 reason in the comments and tag a friend to let them know"). All other questions were fully procedural or promotional ("Got a phone? Got Internet? GET HIS BACK. Call.barackobama.com"; "Voting by mail? Put a stamp on that ballot and send it in today"; "Would you describe yourself as a 'talker'? 
TABLE 5. User Interaction with Different Types of Rhetorical Device

\begin{tabular}{|c|c|c|c|c|c|}
\hline $\begin{array}{l}\text { All posts } \\
(N=163)\end{array}$ & $n$ & $\%$ & $\begin{array}{c}\text { Mean } \\
\text { likes } \\
\text { per post }\end{array}$ & $\begin{array}{c}\text { Mean } \\
\text { comments } \\
\text { per post }\end{array}$ & $\begin{array}{c}\text { Mean } \\
\text { shares } \\
\text { per post }\end{array}$ \\
\hline Call to action & 113 & 69.3 & 179,970 & 12,224 & 21,867 \\
\hline $\begin{array}{r}\text { Personal } \\
\text { appeal }\end{array}$ & 97 & 59.5 & 170,743 & 11,572 & 22,062 \\
\hline Quote & 49 & 30.1 & 221,241 & 14,894 & 23,437 \\
\hline Urgency & 45 & 27.6 & 151,480 & 10,482 & 15,409 \\
\hline $\begin{array}{l}\text { Policy } \\
\text { statement }\end{array}$ & 42 & 25.8 & 177,753 & 13,786 & 25,601 \\
\hline $\begin{array}{l}\text { Collective } \\
\text { appeal }\end{array}$ & 41 & 25.2 & 195,118 & 12,192 & 22,654 \\
\hline Fact/statistic & 22 & 13.5 & 139,762 & 11,091 & 14,606 \\
\hline Humor & 10 & 6.1 & 257,067 & 11,977 & 21,082 \\
\hline Question & 9 & 5.5 & 187,568 & 11,961 & 14,365 \\
\hline
\end{tabular}

Hit the phones for the president if you've got

Barack's back").

Calls for action and personal appeal (i.e., the use of imperative mood in the sentence structure toward the reader, prompting some sort of action in response to the post) were the two most-used

760 rhetorical devices (see Table 5). Interestingly, on Howard Dean's blog during the 2004 primaries campaign, only one-quarter of posts focused on making the reader feel part of the campaign (Trammell et al., 2006), while $71.8 \%$ of posts

765 in Obama's 2012 campaign used personal or collective appeal. This could be attributed to a number of factors, such as the much more direct and personal mode of communication on Facebook, the increasing importance of person-

770 alization in contemporary political culture, and the fact that the Obama campaign has strategically and consistently utilized social media to mobilize public support and facilitate a sense of belonging (Katz et al., 2013; Lilleker \& Jackson, 775 2011).

The prominence of mobilization is evident in the campaign's Facebook strategy, with $69.3 \%$ of posts prompting engagement in a wide range of subcategories recognized (see Table 6). Seven

780 types of call to action were recognized, with "prompting to share" being mostly used. The implied message in most posts was to use the native share function on Facebook to spread the message and make Obama's campaign more
TABLE 6. User Interaction with Different Types of Call to Action

\begin{tabular}{|c|c|c|c|c|c|}
\hline $\begin{array}{l}\text { Call to action } \\
\text { posts }(n=113)\end{array}$ & $n$ & $\%$ & $\begin{array}{c}\text { Mean } \\
\text { likes } \\
\text { per post }\end{array}$ & $\begin{array}{c}\text { Mean } \\
\text { comments } \\
\text { per post }\end{array}$ & $\begin{array}{c}\text { Mean } \\
\text { shares } \\
\text { per post }\end{array}$ \\
\hline Call to share & 41 & 36.3 & 221,204 & 14,557 & 36,450 \\
\hline Show support & 22 & 19.5 & 172,682 & 10,789 & 12,987 \\
\hline Vote & 18 & 15.9 & 214,071 & 13,549 & 21,444 \\
\hline Find out more & 15 & 13.3 & 133,789 & 12,420 & 13,235 \\
\hline Donate & 15 & 13.3 & 125,883 & 11,113 & 11,124 \\
\hline $\begin{array}{l}\text { Buy/special } \\
\text { offer }\end{array}$ & 5 & 4.4 & 72,241 & 4,677 & 4,000 \\
\hline $\begin{array}{l}\text { Join } \\
\quad \text { competition }\end{array}$ & 4 & 3.5 & 67,807 & 6,401 & 4,645 \\
\hline
\end{tabular}

visible on the social media platform. Donations 785 are only mentioned in $9.2 \%$ of posts overall, compared to Howard Dean's blog campaign in 2003 and 2004, which encouraged donations in $15.7 \%$ of posts (Trammell et al., 2006). However, Obama's campaign encouraged individual involvement (show support, share) in $38.7 \%$ of overall posts compared to Dean's $12.5 \%$ (Trammell et al., 2006), illustrating a more intensive usage of social media to mobilize grass roots and disseminate information (Sweetser \& Lariscy, 2008), but also a strategy that is much more professional and segmented in order to match the particular traits and user trends of each platform.

Finally, the language employed across posts largely constitutes a very personal and direct communication approach. As indicated earlier, much focus is placed on President Obama himself, as well as employing personal appeals that attempt to close the discursive and political gap between the reader and the candidate. Words such as you, your, you've, you're, and yours occur 136 times throughout the 163 posts. Additionally, the words we, we've, us, and our occur 67 times, and the word friend or friends occurred 19 times in the context of phrases such as "let your friends know" or "your friends should see this." Facebook's core purpose of connecting people was appropriated by the Obama campaign as it sought to emulate the interpersonal connectivity that is native to the platform. 
820

\section{User Response and Engagement: Rewarding Positivity; Resisting Promotions}

As mentioned earlier, the great majority of the Obama campaign's Facebook posts in the runup to the election featured images. We found that the presence of Obama in a photo post had a statistically significant positive effect on the number of likes $(r=.373, p<.001)$, comments $(r=.363, p<.001)$, and shares $(r=.265, p=$ $.002)$ it received. The presence of the First Lady Michelle Obama or of Obama's daughters in a photo had an even more engaging effect: such posts received on average $70 \%-80 \%$ more likes than the other most popular type of post category, that is, photos featuring the president on his own.

Our analysis of campaign followers' reactions to its Facebook posts produced a surprising dichotomy: substantive posts (about policy or even about Obama's character) were far more engaging and successful in getting people to share them than personal appeals and promotional calls. One major exception to that was Calls to Share: such prompts had a statistically significant effect on likes $(r=.199, p=.015)$ as well as on actual shares $(r=.309, p<.001$; the average number of shares for posts when prompted to do so was 36,450 , while for all other posts the average was 15,508 shares) and even more so when that prompt was embedded in a photo $(r=.444, p<.001)$, regardless of whether the president appeared in the photo or not.

It is worth pointing out that one of the two text-only posts received significantly higher levels of attention (230,000 likes, 7,126 comments, and 9,006 shares) than the other:

President Obama: "We don't turn back. We leave no one behind. We pull each other up." If this sounds like the America you believe in, keep us moving forward: http://OFA.BO/FzuNUHSeptember 7, 2012

In contrast, the other post received only 22,469 likes, 5,212 comments, and 664 shares:
Last call: Enter before midnight for 865 your chance to join Beyoncé, Jay-Z, and President Obama for an evening in New York. We'll fly you in with a guest: http://OFA.BO/eW6Anj-September, 14, 2012

This contrast in user responses to the two types of messages (value-oriented emotive message versus promotional) is precisely typical of how followers reacted to the campaign on Facebook. It also reiterates the power of language, even when there is no visual aid.

Furthermore, during the 67-day period, the campaign posted seven videos on the official Facebook page. Our analysis shows that these videos failed to engage users: posts featuring a video had a statistically significant negative correlation with the number of likes $(\beta=-.358$, $p<.001)$, comments $(\beta=-.276, p=.003)$, and shares $(\beta=-.235, p=.012)$. In fact, video posts received much less interactions even than text-only posts (see Table 7). The reason for this may be the extra time and effort required

\section{TABLE 7. User Interaction with Posts Featuring Photos}

\begin{tabular}{|c|c|c|c|c|c|}
\hline $\begin{array}{l}\text { Picture posts } \\
(n=154)\end{array}$ & $n$ & $\%$ & $\begin{array}{l}\text { Mean } \\
\text { likes } \\
\text { per post }\end{array}$ & $\begin{array}{c}\text { Mean } \\
\text { comments } \\
\text { per post }\end{array}$ & $\begin{array}{c}\text { Mean } \\
\text { shares } \\
\text { per post }\end{array}$ \\
\hline $\begin{array}{l}\text { Barack } \\
\text { Obama }\end{array}$ & 78 & 50.6 & 246,610 & 15,392 & 27,941 \\
\hline People & 40 & 26.0 & 159,986 & 9,337 & 11,103 \\
\hline Policy & 33 & 21.4 & 159,679 & 14,132 & 25,109 \\
\hline Quote & 32 & 19.3 & 222,838 & 16,300 & 27,487 \\
\hline $\begin{array}{l}\text { Michelle } \\
\text { Obama }\end{array}$ & 18 & 11.7 & 310,975 & 14,167 & 26,222 \\
\hline Politicians & 17 & 11.0 & 163,319 & 14,490 & 21,156 \\
\hline Promotions & 11 & 7.1 & 61,374 & 6,274 & 4,133 \\
\hline Joe Biden & 10 & 6.5 & 270,473 & 14,470 & 26,802 \\
\hline $\begin{array}{l}\text { Prompting to } \\
\text { share }\end{array}$ & 9 & 5.8 & 265,159 & 14,799 & 72,516 \\
\hline Event & 7 & 4.5 & 88,728 & 7,055 & 6,585 \\
\hline Celebrities & 4 & 2.6 & 71,951 & 4,662 & 7,430 \\
\hline $\begin{array}{l}\text { Obama's } \\
\text { daughters }\end{array}$ & 3 & 1.9 & 449,420 & 15,061 & 32,904 \\
\hline Map & 3 & 1.9 & 75,305 & 7,681 & 6,273 \\
\hline $\begin{array}{l}\text { Obama and } \\
\text { Michelle }\end{array}$ & 10 & 6.5 & 421,482 & 20,158 & 39,097 \\
\hline $\begin{array}{l}\text { Obama and } \\
\text { daughters }\end{array}$ & 3 & 1.9 & 449,420 & 15,061 & 32,904 \\
\hline
\end{tabular}


to digest the message in a video. Although the message in an image or text is instantly 890 apparent, a video requires playing and watching the video (which in turn requires adequate bandwidth, sound, and privacy). This may suggest that videos are less efficient at reaching a Facebook audience whose News Feeds are 895 already saturated with updates from friends and other fan pages. Or it could merely indicate that campaign followers have particular expectations (and receive the corresponding gratifications) from different platforms, such as Facebook, 900 Twitter, and YouTube. Hence, Facebook may not be a particularly efficient way of promoting a video.

Moving to how users engaged with different types of rhetoric and post content, the 905 literature on political rhetoric and persuasion has long acknowledged the salience of the three elements of Aristotelian rhetoric (logos, pathos, and ethos) and the impact of political messages that are "reasonable, passionate,

910 and reflective of the character of the speaker" (Triadafilopoulos, 1999, p. 741), respectively. Our analysis shows that posts making use of one or more of those elements were much more engaging (see Figure 5). Emotive language in 915 particular dominates much of the campaign on Facebook, being employed in more than half of the posts (see Table 8) and emerged as one of the three most impactful variables (the other two being photos of Obama and prompts to share). 920 The use of pathos seems to have struck a chord with campaign followers because emotional
TABLE 8. User Interaction with Posts Featuring Elements of Aristotelian Rhetoric

\begin{tabular}{lccccc}
\hline $\begin{array}{l}\text { All posts } \\
(N=163)\end{array}$ & $n$ & $\%$ & $\begin{array}{c}\text { Mean } \\
\text { likes } \\
\text { per post }\end{array}$ & $\begin{array}{c}\text { Mean } \\
\text { comments } \\
\text { per post }\end{array}$ & $\begin{array}{c}\text { Mean } \\
\text { shares } \\
\text { per post }\end{array}$ \\
\hline $\begin{array}{l}\text { Pathos } \\
\quad(\text { emotion) }\end{array}$ & 94 & 57.7 & 226,687 & 14,153 & 25,782 \\
$\begin{array}{l}\text { Ethos } \\
\quad \text { (credibility) }\end{array}$ & 68 & 41.7 & 226,865 & 14,939 & 24,893 \\
$\begin{array}{l}\text { Logos (logic) } \\
\text { None }\end{array}$ & 37 & 22.7 & 167,142 & 14,565 & 24,195 \\
\hline & 39 & 23.9 & 118,236 & 8,559 & 10,386 \\
\hline
\end{tabular}

acclaims received on average 50,000 more likes than nonemotional ones. Similarly, $59.5 \%$ of posts denigrating the opponent used emotional language compared to $24.4 \%$ in the 2004 campaign between George Bush and John Kerry (Trammell et al., 2006).

Words such as care, trust, cheer on, fired up and fighting for were seen as appealing to emotions, and, contrary to Bronstein (2013), we found that this type of discourse did have a significant impact on how much people liked $(\beta=$ $\left..273, \eta_{\rho}^{2}=.080, p<.001\right)$, commented on $(\beta=$ $\left..208, \eta_{\rho}^{2}=.053, p=.006\right)$, and shared posts $(r=.213, p=.007)$ even when having controlled for the presence of photos and prompts to share. This is in line with the contentions that the emotional dimension of rhetoric is an increasingly vital part of contemporary political communication and youth engagement with the potential to initiate their involvement and influence their voting choice (Brader, 2005).

FIGURE 5. User interaction with posts featuring emotional appeal.
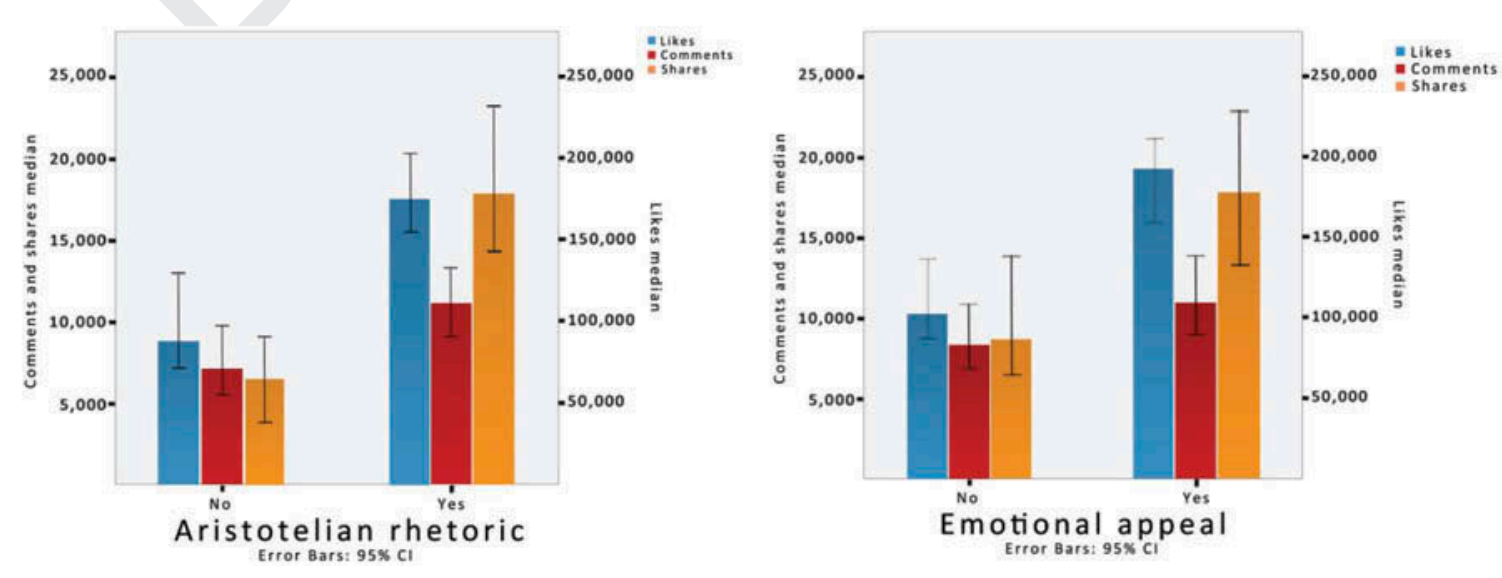
The campaign was also successful in engaging followers with messages focusing on 945 Obama's ethos, that is, his credibility and status, because such messages received more likes $(U=1981, p<.001)$, comments $(U=2851.5$, $p<.001)$, and shares $(U=1964, p<.001)$ than non-ethos posts. The strategic emphasis on hope 950 and enthusiasm, as opposed to the use of negative or attack messages, was rewarded by followers: positive acclaims were more likely to be shared than other types of posts $\left(\eta_{\rho}^{2}=.043\right.$, $p=.016)$ even when controlling for prompts to

955 share, which as mentioned below emerged as a key factor.

The inclusion of logical reasoning (logos) did not increase the likelihood of a post receiving more likes. This is interesting as it may 960 indicate the limits of reason in contemporary political discourse (or it could simply mean that the Obama campaign was just not as good at framing logical arguments as they were at projecting emotions and credibility). However,

965 citizens who followed the Obama campaign on Facebook were willing to engage in a public dialogue on posts that utilized rational argumentation, because the use of logos had a statistically significant relationship with the number 970 of shares $(U=1489, p=.001)$ and comments $(U=1826, p=.045)$ and they still engaged substantively with policy content (see Table 9). This can actually be attributed to the presence of particular policy themes: education posts were by 975 far the most popular, while statements on taxes $\left(\eta_{\rho}^{2}=.029, p=.045\right)$ and foreign policy $\left(\eta_{\rho}^{2}=\right.$

TABLE 9. User Interaction with Different Policy Areas and Issues

\begin{tabular}{lccccc}
\hline $\begin{array}{l}\text { Policy } \\
\text { statements } \\
(n=42)\end{array}$ & $\mathrm{n}$ & $\%$ & $\begin{array}{c}\text { Mean } \\
\text { likes per } \\
\text { post }\end{array}$ & $\begin{array}{c}\text { Mean } \\
\text { comments } \\
\text { per post }\end{array}$ & $\begin{array}{c}\text { Mean } \\
\text { shares } \\
\text { per post }\end{array}$ \\
\hline $\begin{array}{l}\text { Unemployment } \\
\text { Women's }\end{array}$ & 11 & 26 & 170,319 & 17,531 & 23,778 \\
$\quad$ Rights & 11 & 26 & 183,370 & 12,021 & 26,774 \\
Taxes & 10 & 24 & 156,003 & 22,259 & 21,557 \\
Education & 9 & 21 & $\mathbf{2 1 4 , 3 6 4}$ & 19,221 & $\mathbf{2 7 , 9 6 1}$ \\
Economy & 9 & 21 & 198,031 & 21,511 & 24,759 \\
Health Care & 8 & 19 & 160,236 & 13,182 & 22,466 \\
$\begin{array}{l}\text { Foreign Policy } \\
\text { Energy }\end{array}$ & 4 & 10 & 198,729 & 22,213 & 26,897 \\
\hline & 4 & 10 & 170,432 & $\mathbf{2 3 , 8 2 8}$ & 24,812 \\
\hline
\end{tabular}

$.027, p=.052$ ) attracted significantly greater numbers of comments, having controlled for the presence of a photo.

On the other hand, posts featuring actionoriented personal appeal (e.g., "If you're standing with the president, we've got a free sticker for you" or "Make sure your friends and family know the choice on taxes in this election") were less likely to be liked ( $U=2515, p=.020)$. Similarly, we found that posts about competitions $(\beta=-.173, p=.017)$, promotional links $(\beta=-.235, p=.029)$, and photos of celebrities $(\beta=-.318, p=.045)$ received significantly less user interaction.

\section{DISCUSSION: THE POWER AND LIMITS OF POLITICAL PERSONALIZATION}

Our analysis showed that the Obama campaign made highly strategic and focused use of Facebook as a tool for promoting its key messages and, crucially, for mobilizing supporters to act on its behalf. The main focus of the posts was Obama's personality and family, while rhetorically, the campaign depended 1000 mostly on emotions (pathos) and to a lesser extent on credibility (ethos). Although policy statements did feature during the sampled period, they were obscured by a preoccupation with Obama's character and also by daily calls 1005 to action. These findings largely concur with recent studies (Bronstein, 2013; Katz, Barris \& Jain, 2013; Lilleker \& Jackson, 2011; Serazio, 2014) that challenge the widespread perception of the Obama campaign's digital presence 1010 as revolutionary and emphasize the continuing importance of campaign strategy.

A closer look at Obama's own style, as well as of the particular political context within which the 2012 campaign took place, 1015 offers an interesting explanation for the campaign's focus on personality rather than record. Foley (2013) argues that the gap between Obama's grand rhetorical vision and everyday policy pragmatism has produced a cer- 1020 tain kind of presidential ambiguity that hampers his attempt to connect with the American people. Negotiating that gap-which involves 
defending, contextualizing, and explaining com-

1025 plex policies and decisions that the president may genuinely believe to be the right ones-is a process of translation that requires substantive engagement with people's realities and knowledge gaps. This process has been impeded not

1030 only by Obama's own style of decision making, which tends to be introverted and reflective (Foley, 2013), but also by the actions of other actors in the public sphere of the United States. Furthermore, the adverse economic cir-

1035 cumstances of Obama's first term have meant that a core part of his record could only be framed as what Foley calls a "negative achievement," that is, the economy not getting worse. In this context, the capacity of new media such

1040 as Facebook to allow for potentially direct communication between the president and the public could have provided him with a way of bypassing the "noise" produced by other political actors.

1045 Despite the intensive use of personalization in a rhetorical attempt to close the gap between the candidate and his supporters, the discourse of the Obama campaign on Facebook was highly managed and close-ended: only one out of

1050163 posts asked followers to consider what could be classified as a substantive question. Therefore, although the campaign successfully used Facebook to extend and mobilize its fan base, the strategic discourse did not encourage

1055 the creation of loops of feedback, which are key to building a dialogic relationship (Kent \& Taylor, 1998). By focusing on Obama's family and personality, the campaign essentially controlled the discussion, because neither of

1060 these topics is particularly conducive to substantive and in-depth political engagement on the part of the citizens. Although policy discourse could be equally close-ended, readers may hold strong opinions and be prepared to artic1065 ulate them, challenging the official message. Hence, our evidence concurs with BaldwinPhilippi (2012), who identified and described emerging aspects of indirect and discreet control exercised by political campaigns on the

1070 Web, such as self-censorship, determining what participants will talk about (agenda-setting), focusing on winnable topics, and nonissue coverage.
Vaccari (2010) argues that Obama's 2008 campaign use of innovative forms of 1075 political communication, such as data-assisted guidance, constituted a hybrid model of topdown control and bottom-up empowerment (while also noting the tensions that occasionally occur between the two). Yet, postmodern 1080 personalization and strategic segmentation are different from real empowerment and dialogue, especially when the outcome and substance of the campaign's policies, issue responses, and overall discourse are entirely managed from the 1085 center. In other words, the fact that political advertising (because this is essentially what the Obama campaign's Facebook posts constituted) is becoming much more sophisticated and rhetorically personalized does not make it any 1090 less strategic. On the contrary, it is precisely this unprecedented level of organization and discipline - translating into a highly integrated and strategic use of new media-that, according to previous studies, was vital to the Obama 1095 campaign's success in 2008 (Cogburn \& Espinoza-Vasquez, 2011). Although Facebook posts on the campaign's official page may not be the ideal vehicle for microtargeted messages, the increasing sophistication, scope, and reach 1100 of Facebook's personalization algorithm (see Gerodimos \& Gray, 2013)—along with a strategic shift toward the integration of ads into the News Feed may soon allow that kind of campaigning to take place through Facebook, 1105 too.

Directing Facebook followers to spread the campaign's message may signify an important change in terms of where and how political campaigning takes place, but it does not nec- 1110 essarily constitute a paradigm shift in terms of truly interactive communication between politicians and citizens. Having said that, even closeended and strategic rhetoric, almost by definition, entails the agency of citizens, its success 1115 depending on the extent to which it can capture the moment and articulate issues, conflicts, or sociopolitical cleavages that are salient among the people (kairos and stasis, respectively; see Martin, 2013). In other words, political broad- 1120 casting requires an acute understanding of how citizens feel and what they need; listening is a prerequisite of successful strategic rhetoric. 
Furthermore, the act and process of engag1125 ing with a campaign may well have multiple benefits for a citizen's civic skills (such as political sophistication), social capital, and overall participation. In fact, Bode (2012) argues that, through interaction, conversation, and possible 1130 preference alteration, Facebook use may not just lead to civic skills but may also influence users. In that respect, future research should try to look at the effects and benefits of civic interaction on social media beyond the instances of 1135 communication itself.

At this point, the limitations of the study should be acknowledged. Although our analysis captured every message posted in the two months before the 2012 election, this sample is 1140 still a partial snapshot in the context of a massive and multimedia campaign that had started several months before Election Day. Furthermore, due to the study's angle, we did not log or analyze the content of comments posted by follow1145 ers on the campaign's various posts. Although such an undertaking would have certainly produced valuable insights regarding the quality, nature, and depth of civic deliberation among Obama's followers, it fell outside of this partic-

1150 ular analysis's remit. The number of interactions each post received is a metric that can only provide tentative and indicative findings of what content people are more likely to engage with on Facebook. A broad range of elements will influ-

1155 ence that process of engagement: users' personal attitude to politics and social media use, their habits in using social media (some never like, others always like), the temporal and geographical context around a particular message, the cultural and social context around the sent message, and the individual's situational context (mood, in a rush, personal bias). It is impossible to measure all of these on a large scale. However, significant associations were estab1165 lished, revealing — or rather, suggesting — a general tendency or inclination to engage more with particular themes or types of rhetoric. Although users exposed to published messages are in the first instance those who have liked (effectively

1170 subscribed to) Obama's official Facebook page, hence implying a Democrat inclination in a majority of the target audience, when an individual likes or shares a post, this becomes visible to their networks, exposing other Facebook users to the published messages as well.

Finally, as our intention was to look at merely what was "on the page" and how users engaged with that material at the basic level of using Facebook's features, we cannot make conclusive claims about the intentions of the campaign's 1180 communication strategists or, indeed, about any long-term effects on the followers or the externalities of the messages communicated through that page. Still, our analysis produced a rich body of data that provides us with important 1185 insights regarding both the 2012 Obama campaign itself and, more broadly, about emerging patterns of online political communication and engagement.

Further qualitative research is needed into 1190 the motivations, meanings, and significance of a Facebook interaction (like/comment/share) to the platform's users. For example, does a "like" only express positive sentiments? How much affinity or endorsement is usually a prerequi- 1195 site to liking content (merely superficial and impulsive response or significant and meaningful agreement)? And how does an individual decide what to share and what not to?

Thinking more broadly in terms of the rela- 1200 tionship between new media and political communication, our analysis of the 2012 Obama Facebook campaign revealed elements of both normalization (focus on candidate, underutilization of the medium's potential) and innova- 1205 tion (more positive tone, space for debate even if the discourse is close-ended). Despite noting that the claims of postmodern campaigning are overstated, Larsson (2013) argues that the potential for structural change rests with 1210 politicians and with citizens, because both sides have the resources to enforce change. As shown earlier, the Obama campaign's followers were quite selective in what types of messages they interacted with, largely overlooking promotional 1215 posts such as calls to action and celebrity endorsements, and engaging with character and family messages as well as policy statements, which would seem to go against fears of "dumbing down."

The question then arises: is the highly sophisticated, digitized, and personalized permanent campaign inherently at odds with a mode 
of substantive citizen-politician communication 1225 and even coproduction of political ideas? Will it ever be possible - and is it even desirable - to combine the efficiency, highly strategic messages, centralized operations, and war-like mentality of political campaigning with substantive

1230 forms of civic interaction? Such civic input, if not necessarily shaping policy, could at least enhance both politicians' understanding of the reality on the ground and citizens' understanding of the complexities and constraints of con1235 temporary policy making in a highly globalized, decentralized, and interdependent world. Such dialogue might have significant benefits for both sides, boosting empathy and systemic trust, even if politicians were to stand their ground (which 1240 might actually enhance their popular standing).

\section{ACKNOWLEDGMENTS}

An early draft of this paper was presented at the ECREA Political Communication Section Conference, "New Trends in

1245 Political Communication: Evidence, Theories, Implications, Opportunities," September 19-20, 2013, in Milan, Italy. The authors wish to thank the participants of that conference, JITP's three anonymous referees for their very helpful 1250 suggestions, and Samir Bhatti for his assistance with the statistical analysis.

\section{NOTE}

1. Because the recording of posts only started on October 10, 2012, the samples were initially divided into two groups; post interactions from before October 10

1255 (39 days) were recorded after the post had been published for a while. For example, a post from September $10 \mathrm{had}$ a month of exposure when recorded while a post from October 1 merely had 10 days of exposure, potentially compromising the comparability of the number of interac1260 tions, because these accumulate over an indefinite period of time. Samples recorded after October 10 were consistently recorded every day. To counter this potential limitation, a preliminary analysis was carried out to establish if these two groups of posts could be compared. The number of

1265 interactions in every post gathered after October 10 was recorded repeatedly in the first five days after a post was published to establish whether there was a saturation threshold after which interaction with the post diminished. The purpose of this was to ensure that the number of interactions in posts recorded more than five days after 1270 they were published could be compared to other posts. Our preliminary analysis showed that the number of new interactions receded considerably after the third day and almost ceded five days after a post was originally published, indicating that older posts coded after several days 1275 of exposure and newer posts coded consistently after five days constituted a homogeneous and workable sample.

\section{REFERENCES}

Baldwin-Philippi, J. (2012). Using technology, building democracy: How political campaigns' uses of 1280 digital media reflect shifting norms of citizenship (Doctoral dissertation). Northwestern University, Evanston, IL. Retrieved from http://gradworks.umi. com/35/08/3508269.html

Benoit, P. J., \& Benoit, W. L. (2005). Criteria for evaluating 1285 political campaign webpages. Southern Communication Journal, 70(3), 230-247.

Bode, L. (2012). Facebooking it to the polls: A study in online social networking and political behavior. Journal of Information Technology \& Politics, 9(4), 352-369.

Brader, T. (2005). Striking a responsive chord: How political ads motivate and persuade voters by appealing to emotions. American Journal of Political Science, 49(2), 388-405.

Bronstein, J. (2013). Like me! Analyzing the 2012 presi- 1295 dential candidates' Facebook pages. Online Information Review, 37(2), 173-192.

Carlisle, J. E., \& Patton, R. C. (2013). Is social media changing how we understand political engagement? An analysis of Facebook and the 2008 presiden- 1300 tial election. Political Research Quarterly, 66(4), 883-895.

Cogburn, D. L., \& Espinoza-Vasquez, F. K. (2011). From networked nominee to networked nation: Examining the impact of Web 2.0 and social media on political 1305 participation and civic engagement in the 2008 Obama campaign. Journal of Political Marketing, 10(1), 189-213.

Compton, J. (2008). Mixing friends with politics: A functional analysis of '08 presidential candidates' social 1310 networking profiles. Paper presented at the NCA (National Communication Association) 94th Annual Convention, November 21-24, San Diego, CA.

Endres, D., \& Warnick, B. (2004). Text-based interactivity in candidate campaign Web sites: A case study from 1315 the 2002 election. Western Journal of Communication, $68(3), 322-342$. 
Facebook (2013). Facebook reports fourth quarter and full year 2012 results. Retrieved March 1, 2013 from http:// investor.fb.com/releasedetail.cfm?ReleaseID $=736911$

1320

Foley, M. (2013). Barack Obama and the calculus of presidential ambiguity. Political Studies Review, 11(3), 345-357.

Forbes (2013). Facebook designer explains News Feed facelift [video]. Available from http://www.forbes. com/sites/jeanbaptiste/2013/03/07/facebook-designerexplains-news-feed-facelift-video/

Gerlitz, C., \& Helmond, A. (2013). The like economy: Social buttons and the data-intensive Web. New Media \& Society, online. doi:10.1177/1461444812472322

Gerodimos, R. (2008), Mobilising young citizens in the UK: A content analysis of youth and issue websites. Information, Communication \& Society, 11(7), 964-988.

1335 Gerodimos, R. (2012). Online civic attitudes and the limits of civic consumerism. Information, Communication \& Society, 15(2), 217-245.

Gerodimos, R., \& Gray, T. (2013). The Web of one: Web personalisation v. user satisfaction on Facebook.

1340 Paper presented at the PSA Media and Politics Group Annual Conference, November 13-14, Bournemouth University, UK.

Hampton, K., Goulet, L. S., Rainie, L., \& Purcell, K. (2011). Social networking sites and our lives. Retrieved

1345 from Pew Research Internet Project Web site: http:// www.pewinternet.org/Reports/2011/Technology-andsocial-networks/Summary.aspx

Harvard University Institute of Politics (2011). Spring 2011 survey. Retrieved from http://www.iop.harvard. edu/spring-2011-survey

Himelboim, I., Lariscy, R. W., Tinkham, S. F., \& Sweetser, K. D. (2012). Social media and online political communication: The role of interpersonal informational trust and openness. Journal of Broadcasting and Electronic Media, 56(1), 92-115.

Hong, S., \& Nadler, D. (2012). The use of social media by 2012 presidential candidates and its impact on candidate salience. Government Information Quarterly, 29(4), 455-461.

1360 Jackson, N. A., \& Lilleker, D. G. (2009). Building an architecture of participation? Political parties and Web 2.0 in Britain. Journal of Information Technology \& Politics, $6(3), 232-250$.

John, N. A. (2013). Sharing and Web 2.0: The emer1365 gence of a keyword. New Media and Society, 15(2), 167-182.

Katz, J., Barris, M., \& Jain, A. (2013). The social media president: Barack Obama and the politics of digital engagement. Basingstoke, UK: Palgrave Macmillan.

1370 Kent, M. L., \& Taylor, M. (1998). Building dialogic relationships through the World Wide Web. Public Relations Review, 24(3), 321-334.
Kienpointner, M. (2013). Strategic maneuvering in the political rhetoric of Barack Obama. Journal of Language and Politics, 12(3), 357-377.

Kirkpatrick, D. (2010). The Facebook effect: The inside story of the company that is connecting the world. London, UK: Simon and Schuster.

Larsson, A. O. (2013). Rejected bits of program code: Why notions of "Politics 2.0" remain (mostly) unfulfilled. 1380 Journal of Information Technology \& Politics, 10(1), 72-85.

Lilleker, D. G. (2006). Key concepts of political communication. London, UK: Sage.

Lilleker, D. G., \& Jackson, N. A. (2011). Political cam- 1385 paigning, elections and the Internet. London, UK: Routledge.

Martin, J. (2013). Situating speech: A rhetorical approach to political strategy. Political Studies. Advance online publication. doi:10.1111/1467-9248.12039

Metzgar, E., \& Maruggi, A. (2009). Social media and the 2008 U.S. presidential election. Journal of New Communications Research, 4(1), 141-165.

Negrine, R., \& Lilleker, D. G. (2002). The professionalization of political communication: Continuities 1395 and change in media practices. European Journal of Communication, 17(3), 305-323.

Pariser, E. (2011). The Filter bubble. London, UK: Penguin Books.

Pearson, S., \& O'Connell, F. (2012, June). On point on 1400 Twitter. Campaigns and Elections. Retrieved from http://www.campaignsandelections.com/magazine/ 1853/on-point-on-twitter

Rainie, L., \& Smith, A. (2012). Politics on social networking sites. Retrieved from http:// 1405 pewinternet.org/ /media//Files/Reports/2012/ PIP_PoliticalLifeonSocialNetworkingSites.pdf

Reddit. (2012). I am Barack Obama, president of the United States-AMA. Retrieve April 16, 2013 from http://www.reddit.com/r/IAmA/comments/z1c9z/ i_am_barack_obama_president_of_the_united_states

Saldaña, J. (2009). The Coding manual for qualitative researchers. London, UK: Sage.

Semiocast (2012). Twitter reaches half a billion accounts. Retrieved March 1, 2013 from http://semiocast.com/ 1415 publications/2012_07_30_Twitter_reaches_half_a_ billion_accounts_140m_in_the_US

Serazio, M. (2014). The new media designs of political consultants: Campaign production in a fragmented era. Journal of Communication, 64(4), 743-763.

Sweetser, K. D., \& Lariscy, R. W. (2008). Candidates make good friends: An analysis of candidates' uses of Facebook. International Journal of Strategic Communication, 2(3), 175-198.

Trammell, K. D., Williams, A. P., Postelnicu, M., \& 1425 Landreville, K. D. (2006). Evolution of online campaigning: Increasing interactivity in candidate Web sites 
and blogs through text and technical features. Mass Communication and Society, 9(1), 21-44.

1430

Triadafilopoulos, T. (1999). Politics, speech and the art of persuasion: Toward an Aristotelian conception of the public sphere. Journal of Politics, 61(3), 741-757.

Vaccari, C. (2010). "Technology is a commodity": The Internet in the 2008 United States presidential election. Journal of Information Technology \& Politics, 7(4), 318-339.

Vaccari, C. (2013). From echo chamber to persuasive device? Rethinking the role of the Internet in campaigns. New Media and Society, 15(1), 109-127.

Wells, S. D., \& Dudash, E. A. (2007). Wha'd'ya know? Examining young voters' political information and efficacy in the 2004 election. American Behavioral Scientist, 50(9), 1280-1289.

Woolley, J. K., Limperos, A. M., \& Oliver, M. B. 1445 (2010). The 2008 presidential election, 2.0: A content analysis of user-generated political Facebook groups. Mass Communication and Society, 13(5), 631-652. 